\title{
Anderson's athletic identity concept: French-Canadian validation of the athletic identity questionnaire
}

\author{
Pierre-Luc Yao ${ }^{*}$, François Trudeau ${ }^{2}, \&$ Louis Laurencelle ${ }^{3}$ \\ ${ }^{1}$ Departement psychology, Université du Québec à Trois-Rivières, Canada \\ ${ }^{2}$ Department Human kinetics, Université du Québec à Trois-Rivières, Canada \\ ${ }^{3}$ Department Human kinetics, Université du Québec à Trois-Rivières, Canada
}

\begin{abstract}
Introduction: Although sport identity is a notion widely used in the literature to explain one's attachment to the athletic role, a few valid psychometric tools exist in French to measure such notion.

Objective: Validation of a French version of Anderson's (2004) Athletic Identity Questionnaire (AIQ) for a Québec French-speaking population.

Method: Participants $(n=389)$ completed the French version of the AIQ and were athletes, former athletes and non-athletes. Exploratory factor analysis and structural equation modeling were used to examine model structure, whereas ANOVAS helped determine construct validity regarding athletic status.

Results: A four factor first order structure emerged, as well as a second order structure composed of three of the four original facets. Significant differences for all four scales across the three groups appeared.
\end{abstract}

Conclusion: AIQ-French is a valid psychometric tool which can measure different degrees of athletic identity best represented jointly by the importance, appearance and competence scales.

Key words: Validation, Athletic identity, Factor analysis, Psychometrics, French

\section{Introduction}

Athletic identity (AI) among high-level athletes is an important part of their self-definition. It is more powerful than other social identities as it is often established early in athletes' life (Nasco \& Webb, 2006). Identity can be described as the understanding or objectification of the self (Holland, 1997). A person may possess a number of identi-

Submitted : 7 April 2018

Revised : 24 May 2018

Accepted : 20 July 2018

Correspondence : pierre-luc.yao@uqtr.ca ties defined by specific attributes of the self, such as an athletic person in a sport context, and other social roles such student, engineer or singer. These multiple identities are not only hierarchized according to the effort and time invested by an individual in their personification, but also according to the context in which he finds himself (Mccall \& Simmons, 1966). The sports athletes will have an identity that they will prioritize at the expense of their other roles depending on the contribution to their discipline. Athletic identity is described in literature by the degree to which an individual identifies with the athletic role (Brewer, Van Raalte, \& Linder, 1993). Moreover, definition of the self 
in relation to sport is considered to contain multiple dimensions (Anderson, 2004; Brewer et al., 1993). The conceptual model of sport identity has three aspects: social identity, athletic exclusivity and negative affectivity (Brewer et al., 1993). Social identity is the degree to which an individual perceives himself or herself as able to occupy the role and status of an athlete. This vision can also reflect the perceptions of the individual's entourage. Exclusivity refers to selfenhancement guided by performance as an athlete. Finally, negative emotions caused by undesired outcomes in sport refer to the dimension of negative affectivity. The Athletic Identity Measurement Scale (AIMS) is an instrument created to measure this reality of the psychology of sport.

More recently, the Athletic Identity Questionnaire (AIQ) was designed to overcome the conceptual narrowness of previously published instruments (Anderson, 1995, 2004) such as the Sport Identities Index (Curry \& Weaner, 1987), exercise self-schemata (Kendzierski, 1988, 1990), AIMS (Brewer et al., 1993), and the Exercise Identity Scale (Anderson \& Cychosz, 1994). The main interest of these instruments was to measure the strength and exclusivity of self-identification to a specific role in sport (eg, diver, skater, soccer player). These early instruments were, according to Anderson (2004), presented as unifactorial scales. One of the objectives for creating the AIQ-French was to measure the various facets that constitute the identity associated with the practice of physical activity and sport and at the same time transcend all categories of athletes, regardless of the discipline. Another objective was the tool usability in the field of public health or clinical research.

It was stipulated that the general qualification of "being athletic" was determined by the self-assessment of its component dimensions. Athletic identity has therefore been defined a priori by four interconnected dimensions (Anderson, 1995). The first of these dimensions is physical appearance which comes from the self and reflects information about physical look (Swann, 1983). A high score on this scale is associated with the perception of being physically fit. Competence in sport, on the other hand, reflects the belief that one is able to perform well in sports and physical activities. For example, a person with a high self-perceived competence will have confidence in his or her tennis or hockey skills. This dimension is based on the work of (Markus, Cross, \& Wurf, 1990), for whom the system of self and competence are reciprocally linked as an integral part of the individual's characteristics. The third dimension is the importance of sport, exercise and physical activity based on the concepts of commitment and importance of Stryker and Serpe (1982). The athlete assesses his or her level of commitment and emphasis on physical activity, exercise or sport. Levels of engagement and importance should be high when the practice of sport-related activities is prioritized for a given individual (Anderson, 2004). The importance of sport will also be influenced by environmental choices that ensure auto-perception stability. A person with a strong emphasis on sports activities should use the environment (eg. improvise location of practice) and social controls (eg. avoid inopportune appointments) to ensure and facilitate the practice of his or her occupations (Swann, 1983). The support from others is the fourth dimension. Individual self-definition can be developed through social interactions. The athlete assesses the level of social support received from "others" as a practitioner of physical activity and sport. The valorization from others in relation to their practice is an element that can influence athletic identity. "Others" refer to the immediate social environment, such as family, friends or colleagues.

The athletic identity questionnaires, through their use in sports psychology, were brought to cross cultural boundaries. The transcultural validation of a questionnaire requires a non-negligible level of rigor and thoroughness. The aim of the operation is to adapt an instrument written in a foreign language and translate it for a different population by ensuring its psychometric qualities (Vallerand, 1989). For example, Brewer's AIMS is an instrument for measuring sports identity which has been validated in several languages and cultures. It has been used in Greece for university students in the field of physical education (Proios, 2012) and in China to compare the athletic identity between elite Chinese and American athletes (Hin Yue \& Andersen, 2008). AIMS has also been adapted for Brazilian (Silva et al., 2016), Iranian (Sohrabi, 2012) and German contexts (Schmid \& 
Seiler, 2003). All versions of the AIMS previously mentioned were considered valid from a psychometric perspective and have multifactorial structures that differ between samples (Hong Kong sample: 9 items 4 factors, Greek sample: 7 items 3 factors, Brazilian sample: 7 items 2 factors, Iranian same: 17 items 3 factors, German: 7 items 3 factors). From this liste we can humbly assume that cultural context seems to play a role when conceptually defining athletic identity. Some studies have made comparisons between different cultural realities in relation to the athletes' self-identification. For exemple French and Swedish athletes have semicomparable levels of athletic identity during their career, which may be explained by their respective social environments. Both countries provide financial support for athletes, and they feel highly recognized and valued for their sports (Stambulova, Stephan, \& Japhag, 2007). In comparison Visek, Watson, Hurst, Maxwell, and Harris (2010) found that Amercan athletes had a higher level of athletic identity than their Hong Kong counterparts. Americain athletes may see sport as means of improving their socioeconomic status and gain access to higher education; as for the Chinese culture, education in itself might be the only indicator of success and sport affects negatively this success by disrupting concentration.

At the psychometric level, virtually all the adaptations regarding athletic identity scales were carried out using methods that included factor analytic models. The objective of such methods is to demonstrate the conceptual validity of a measure, such as athletic identity, and to prove that it truly reflects and covaries with the studied phenomena (Laurencelle, 1998). Much of this research also uses confirmatory factor analysis (CFA) (Joreskog, 1969) and exploratory structural equation modeling (ESEM) (Asparouhov \& Muthén, 2009), based on structural equations, in order to show that the statistical reality fits well with the proposed conceptual model (Cieslak, 2004; Martin, Eklund, \& Mushett, 1997; Proios, 2012). Confirmatory factor analysis (CFA) stands in contrast to classic factor analysis, also termed exploratory factor analysis EFA, the latter imposing no structure on the observed data but aiming to reveal the natural, organic structure that characterizes them (Tabachnick
\& Fidell, 2007). ESEM are, on the other one hand, a method of obtaining an organic arrangement of the data while providing the researcher with indices of adequacy for the underlying factorial model.

To our knowledge, there is no psychometric tool that has been validated in a French speaking context to define athletic identity. For research purposes, such a tool should be clearly aimed at a broad Francophone population, regardless of the level and type of physical activity or sporting practice involved. It would also be necessary to help distinguish levels of identity in relation to current or past sport practice. The relatively unique context of Québec culture seems appropriate to make the AIQ evolve to a different cultural basis. The present study therefore examined this perspective.

The main objective of this study was to translate and validate the Athletic Identity Questionnaire (AIQ) for use in a Francophone Québec population: the original theoretical model of Anderson (2004) represented by four scales and twenty-one items served as a template. The second objective was to verify, using factor analytic model building, whether the structure of the translated test, applied to French Québecers, corresponds to that of the original version. As for the test' discriminant validity, the ability of the AIQ to distinguish among respondents according to their sporting status will be evaluated. Finally, the relationships between the AIQ and AIMS components will serve to establish the former' concurrent validity.

\section{Method}

\section{Participants}

Participants were recruited from a Québec university. This study was approved by the Institutional Ethics Committee of the Université du Québec à Trois-Rivières. All participants provided informed consent before entering in the study. A recruitment e-mail was sent to all of the university's departmental offices, and most of them distributed the questionnaire via their student lists. The content of the message stated the purpose of the research and informed 
participants of the implications of their involvement. The e-mail also contained the intranet link to the electronic questionnaire as well as the instructions for completing it. Initially, 6000 people were solicited via e-mail, and a total sample of 413 participants was obtained. Twenty-four respondents provided incomplete information and were excluded from the analysis. The final sample included 389 participants (103 men, 293 women, 3 unspecified). The age of the respondents ranged between 18 and 62 years (Mean $(M)=24.10$; Standard deviation $(\mathrm{SD})=6.3$ ). The sample included active athletes $(n=52)$, former athletes $(n=141)$ and non-athletes $(\mathrm{n}=196)$. The average age of athletes $(\mathrm{M}=23 ; \mathrm{SD}=5.95)$, former athletes $(\mathrm{M}=23.11 ; \mathrm{SD}=4.42)$ and non-athletes $(\mathrm{M}=24.09 ; \mathrm{SD}=7.29)$

\section{Procedure}

French translation was made be the first author then validated by the second and the third. Once the translation was positively sanctioned, the questionnaire was transferred to an electronic platform to facilitate its diffusion to would-be participants and ease data gathering. For each of the 21 items, a 5-point Likert scale, ranging from 1 (Does not describe me at all/Ne me décrit pas du tout) to 5 (Describes me very well/Me décrit très bien) was used. The French version of the Sport Identity Measurement Scale (AIMS) created by Brewer et al. (1993) and reconfigured by Brewer and Cornelius (2001) was added to the survey with the intention of validating concurrently our translated version of the AIQ. Descriptive questions on age, gender, occupation and level of education were included to better categorise the participants. To classify the sample per athletic status, participants had to answer the question "Do you currently practice high-level sport? / Pratiquez-vous présentement un sport de haut niveau?' High-level sport was defined as competition at the provincial, national or international level. If this first answer was no, the question "Have you ever practiced a high-level sport on a regular basis? / Avez-vous par le passé déjà pratiqué un sport de haut niveau de façon régulière?" was asked. A first positive response assigned the participants in the active athletes (AA) group, a positive followed by a negative response put them in the former athletes (FA) group and two negative responses included them in the non-athletes (NA) group. The purpose of this classification was to verify the AIQ's ability to discriminate according to the participant's athletic status. Active athletes and former athletes were also asked about the type of sport they practiced (present or past). They were subsequently grouped into two sub-categories: collective or individual sport. Participants were also asked to record the number of hours of training they devoted or did devote to their discipline to see the relationship between sport involvement and sports identity scales.

\section{Statistical analyses}

Exploratory factor analyses (EFA), Confirmatory factor analysis (CFA), correlation analyses and analyses of variance (ANOVA) were performed using the SPSS Statistics 23.0 (IBM) software and the structural equation analyses, with version 7.31 of the MPLUS software1.

\section{Results}

The relationships between the four AIQ scales can be seen in Table 1. All inter-scale correlations are positive and significant and range from 0.231 to 0.621 . The most important correlations $(\mathrm{r}>0.55)$ occur between the appearance, competence and importance scales, while the weakest correlations are associated with the support scale. Further scale analyses show the internal consistency of each scale, evaluated by the Cronbach $\alpha$ (alpha) coefficient, varies from 0.827 to 0.913 . The "unitary $\alpha$ " of each of the scales (i.e. scaled down to one item per scale) have values between 0.544 and 0.636 , which are considered acceptable. The mean item-scale correlation is 0.837 for appearance, 0.817 for competence, 0.804 for significance, and 0.811 for support: a Jackknife-type correction (Thorburn, 1976) was used to isolate the correlational input of the item to the total of its scale. The differences between the original and corrected correlations were less than 0.11 on average $(\mathrm{M}=0.105$,

1 Muthen \& Muthen (1998-2015) 
Table 1. AlQ-French between scale correlations

\begin{tabular}{lccccc}
\hline \hline & Appearance & Competence & Importance & Support & AIQ-total \\
\hline Appearance & - & & & & \\
Competence & $0.621^{* *}$ & - & & & \\
Importance & $0.553^{* *}$ & $0.625^{* *}$ & - & & \\
Support & $0.231^{* *}$ & $0.308^{* *}$ & $0.392^{* *}$ & - & - \\
AIQ-total & $0.805^{* *}$ & $0.831^{* *}$ & $0.862^{* *}$ & $0.565^{* *}$ & - \\
\hline \hline
\end{tabular}

*** significant at $\mathrm{p}<0,01$

$\mathrm{SD}=0.035)^{2}$. These unbiased item-scale correlations were also compared with those of the item with the other scales, with each item remaining dominant within its own scale.

An EFA using principal axes factorization and Oblimin type rotations (delta $=0$ ) with Kaiser's normalization was performed in order to unfold the dimensional structure of the instrument. A zero rotation delta was chosen so as not to influence the level of orthogonality (delta $>0$ ) or collinearity (delta $<0$ ) of the factors (Gorsuch, 1983; Gorsuch, 1988). The KMO index obtained was 0.928 and Bartlett's sphericity test was significant $\left(\chi^{2}=5176.21, \mathrm{df}=210, \mathrm{p}<\right.$ 0.001 ). Statistical data and visual examination (trace and loadings matrix) in Table 2 show that four factors are present and account for $68.5 \%$ of the information in the correlation matrix. The first factor includes the six (6) items associated with the importance of physical activity and accounts for $42.31 \%$ of the information. The other factors regroup the items of support from others (4 items, 11.94\%), physical appearance (6 items, $7.81 \%$ ) and competence in sports (5 items, 6.38\%). The between-factor correlations obtained are all positive and range from 0.175 to 0.594 . Scale scores have an average correlation of 0.991 with their corresponding factor score, all these correlations obviously significant. The other correlations between scale and alterfactor scores are also positive, i.e. between 0.195 and 0.629 , and all are significant at $\mathrm{p}<0.01$, reflecting almost exactly the corresponding inter-scale correlations (Table 1). Exploratory structural equation modeling (ESEM) analysis with MPLUS shows a four-factor model with acceptable fit ( $\mathrm{Hu}$

2 Correction based on the Spearman-Brown principle and adapted to the present context
\& Bentler, 1999), $\chi^{2}=311,571, \mathrm{df}=132, \mathrm{p}<0.001 ; \mathrm{CFI}=$ 0.964; TLI $=0.943 ;$ SRMR $=0.022 ; \mathrm{RMSEA}=0.059$ (CI 90 $=0.051-0.068)$. The data were also subjected to confirmatory factor analysis (CFA), the original four-dimensional model being imposed without restricting correlation between latent variables. The estimation by the method of maximum likelihood suggests that the model also seems to go beyond the threshold of acceptability, $\chi^{2}=547,809, \mathrm{df}=188, \mathrm{p}$ $<0.001$; $\mathrm{CFI}=0.928$; TL $=0.918$; SRMR $=0.061$; RMSEA $=0.071(\mathrm{CI} 90=0.065-0.078)$. Table 3 shows a visual of the regressions weights "estimates" of the CFA solution for AIQ. CFA was also used to compare model according to gender, sport status and sport modality. The modelisation across gender was found to be acceptable $\chi^{2}=841.966$, $\mathrm{df}=400, \mathrm{p}<0.001 ; \mathrm{CFI}=0.912 ; \mathrm{TL}=0.908 ; \mathrm{SRMR}=$ 0.077 ; RMSEA $=0.075(\mathrm{CI} 90=0.068-0.082)$ ) with the female having the most important contribution $\chi^{2}=480.977$. For the sport status the AIQ model's acceptability was below the acceptable threshold $\left(\chi^{2}=1104.833\right.$, $\mathrm{df}=617$, $\mathrm{p}<0.001 ; \mathrm{CFI}=0.893 ; \mathrm{TU}=0.891 ; \mathrm{SRMR}=0.089 ; \mathrm{RMSEA}$ $=0.078($ C $90=0.071-0.085))$ with former athletes $\left(\chi^{2}=\right.$ 394.903) and non-athletes $\left(\chi^{2}=390.257\right)$ having similar contributions. Finally, sport modality was not associated with an acceptable model fit $\left(\chi^{2}=657.920, \mathrm{df}=400, \mathrm{p}<\right.$ 0.001; $\mathrm{CFI}=0.898$; $\mathrm{TL}=0.893$; $\mathrm{SRMR}=0.084$; RMSEA $=0.083($ CI $90=0.071-0.094))$. Collective and individual sport had a similar model contribution $\left(\chi^{2}=319.453\right.$ and $\chi^{2}=338.466$ respectively).

The present sample and Anderson's (2004) ${ }^{3}$ were com-

3 Personal communication from Ms B. Anderson (April 9, 2014), who graciously provided us with her raw data file. 
Table 2. AIQ-F First order factor analysis loadings and eigenvalues from EFA

\begin{tabular}{lcccc}
\hline \hline & \multicolumn{4}{c}{ Factors } \\
\cline { 2 - 5 } & 1 & 2 & 3 & 4 \\
\hline Appearance1 & 0.087 & -0.015 & 0.863 & -0.079 \\
Appearance2 & -0.101 & -0.018 & 0.793 & 0.056 \\
Appearance3 & 0.128 & 0.046 & 0.658 & 0.046 \\
Appearance4 & -0.086 & 0.004 & 0.775 & 0.069 \\
Appearance5 & 0.261 & 0.095 & 0.526 & 0.155 \\
Appearance6 & 0.018 & -0.003 & 0.897 & -0.006 \\
Competence1 & 0.072 & -0.031 & 0.085 & 0.493 \\
Competence2 & 0.232 & 0.019 & 0.019 & 0.699 \\
Competence3 & -0.093 & 0.023 & -0.016 & 0.817 \\
Competence4 & -0.014 & 0.048 & 0.047 & 0.833 \\
Competence5 & 0.155 & 0.004 & 0.103 & 0.627 \\
Importance1 & 0.796 & 0.015 & 0.024 & 0.002 \\
Importance2 & 0.592 & -0.003 & -0.099 & 0.163 \\
Importance3 & 0.615 & 0.042 & 0.027 & 0.050 \\
Importance4 & 0.803 & 0.078 & 0.031 & -0.038 \\
Importance5 & 0.621 & 0.009 & 0.027 & 0.183 \\
Importance6 & 0.853 & -0.019 & 0.093 & -0.100 \\
Support1 & 0.153 & 0.635 & 0.088 & 0.007 \\
Support2 & -0.023 & 0.838 & -0.022 & 0.019 \\
Support3 & -0.076 & 0.753 & -0.062 & 0.021 \\
Support4 & 0.022 & 0.701 & 0.034 & -0.036 \\
\hline Eigenvalues & 8.912 & 2.511 & 1.653 & 1.340 \\
\hline \hline
\end{tabular}

bined to determine whether the four-factor structure was appropriate for the two amalgamated populations. EFA results show a solution of four stable correlated factors through the first six iterated solutions. These, repeat satisfactorily the factor model previously obtained with the present sample. The ESEM also shows a four-factor solution with more than acceptable indices of fit $\left(\chi^{2}=389.851, \mathrm{df}=132\right.$, $\mathrm{p}<0.001, \mathrm{CFI}=0.972, \mathrm{TL}=0.956, \mathrm{SRMR}=0.019, \mathrm{RMSEA}$ $=0.049 \% \mathrm{CI}=0.043-0.054)$.

A second analysis was carried out on the basis of the factor scores from the first analysis, the latter being intercorrelated positively, in order to determine the presence and nature of a second order factor structure. Principal component analysis ${ }^{4}$ and the Oblimin (delta $=0$ ) positioning were used. The KMO index obtained here is 0.731 and

4 The choice of the principal component analysis is due to the fact that the second order analysis is applied on factors, pure values, with full variance, obtained previously by the principal axis extraction method.
Table 3. AIQ-F items regressions weights for CFA analysis

\begin{tabular}{lcccc}
\hline \hline & Estimates & S.E. & Est./S.E. & P-Value \\
\hline Appearance1 & 0.845 & 0.017 & 49.116 & 0.000 \\
Appearance2 & 0.755 & 0.024 & 31.053 & 0.000 \\
Appearance3 & 0.776 & 0.023 & 33.938 & 0.000 \\
Appearance4 & 0.756 & 0.024 & 31.481 & 0.000 \\
Appearance5 & 0.802 & 0.021 & 38.031 & 0.000 \\
Appearance6 & 0.878 & 0.015 & 59.664 & 0.000 \\
Competence1 & 0.576 & 0.036 & 15.821 & 0.000 \\
Competence2 & 0.873 & 0.016 & 53.341 & 0.000 \\
Competence3 & 0.726 & 0.027 & 27.048 & 0.000 \\
Competence4 & 0.849 & 0.018 & 46.904 & 0.000 \\
Competence5 & 0.809 & 0.021 & 38.972 & 0.000 \\
Importance1 & 0.812 & 0.020 & 39.956 & 0.000 \\
Importance2 & 0.640 & 0.033 & 19.645 & 0.000 \\
Importance3 & 0.672 & 0.031 & 22.023 & 0.000 \\
Importance4 & 0.832 & 0.019 & 44.014 & 0.000 \\
Importance5 & 0.760 & 0.024 & 31.179 & 0.000 \\
Importance6 & 0.837 & 0.019 & 45.122 & 0.000 \\
Support1 & 0.719 & 0.031 & 23.024 & 0.000 \\
Support2 & 0.828 & 0.025 & 33.288 & 0.000 \\
Support3 & 0.700 & 0.032 & 22.029 & 0.000 \\
Support4 & 0.709 & 0.031 & 22.705 & 0.000 \\
\hline \hline
\end{tabular}

Bartlett's sphericity test $\left(\chi^{2}=521.745, \mathrm{df}=6, \mathrm{p}<0.001\right)$ is significant. Results show the presence of two components in the structure, explaining $82.31 \%$ of the variance. The correlation between the components is 0.316 . The structure matrix clearly shows an organization whose first secondary component, the strongest, combines the primary components appearance, competence and importance, and the other only includes the support component. A second analysis was then carried out using principal component analysis on the factor scores of the appearance, competence and importance factors. The results show a unifactorial structure whose saturations are respectively $0.841 ; 0.886 ; 0.857$. The total variance explained by this model is $74.23 \%$. We verified the relationship between the second order factor 'appearance-competenceimportance' and the total of the three equivalent scales (17 items). These two elements correlate perfectly with one another $(\mathrm{r} \approx 0.995)$. The alpha coefficient for this set of items is 0.935 , the addition of the four support items 

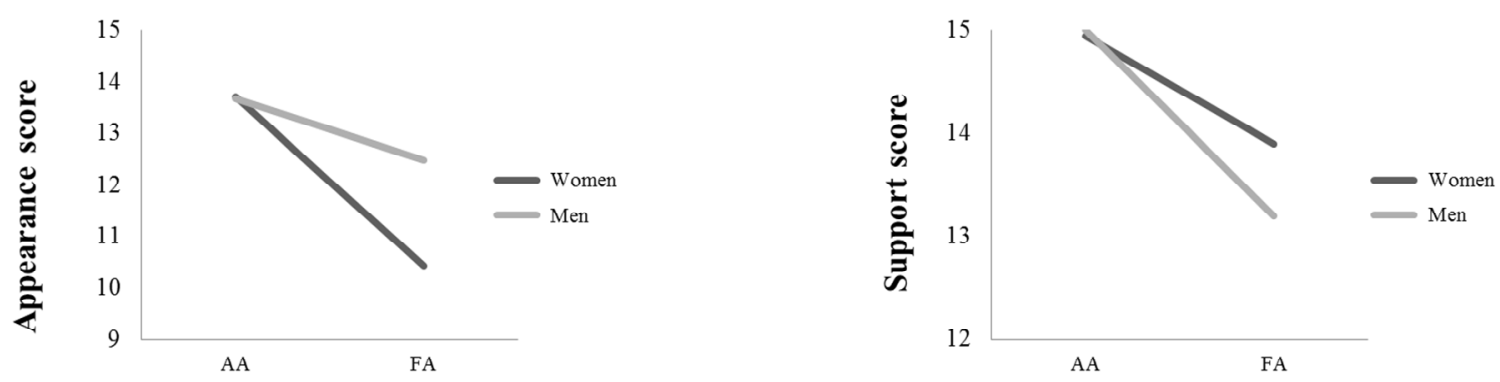

Figure 1. Interaction between sport status and gender for the appearance and support scales

reducing its value to 0.928 . The factor analysis (principal axis) of the 17 items (appearance, competence, importance) also shows a single factor, whose calculated scores correlate perfectly ( $\mathrm{r} \approx 0.996 ; \mathrm{p}<0.01)$ with the total of these same items. The exploratory structural equation modeling (ESEM) yields an acceptable solution which also supports the results of the PCA $\left(\chi^{2}=227.176, \mathrm{df}=88, \mathrm{p}<0.001, \mathrm{CFI}=0.968\right.$, $\mathrm{TLI}=0.951, \mathrm{SRMR}=0.023,(\mathrm{CI} 90=0.054-0.074)$.

ANOVAs were carried out on the total scores of each of the four scales, according to the classificatory variables gender, sport status (active athletes, former athletes, nonathletes) and sporting modality (individual or collective sport $)^{5}$. Significant differences were observed between active athletes, former athletes and non-athletes regarding the appearance scale $(F(2,386)=22.384, p<0.01)$, the competence scale $(\mathrm{F}(2,386)=29.178, \mathrm{p}<0.01)$, the importance scale $(\mathrm{F}(2,386)=30.890, \mathrm{p}<0.01)$ and the support scale $(\mathrm{F}(2,386)=13.664, \mathrm{p}<0.01)$. Men in general had higher scores than women for the appearance scale $(\mathrm{F}(1,386)=$ 22.384, $\mathrm{p}<0.01)$, competence scale $(\mathrm{F}(1,386)=29.178, \mathrm{p}<$ $0.01)$ and importance scale $(\mathrm{F}(1,386)=30.890, \mathrm{p}<0.01)$. No significant difference between genders emerge for the support scale $(\mathrm{F}(1,386)=0.739 ; \mathrm{p}>0.05)$. Concerning sporting modality, only one significant difference between collective sport $(\mathrm{M}=9.48, \mathrm{SD}=3.63)$ and individual sport $(\mathrm{M}=8.24$, $\mathrm{SD}=4.01)$ was observed for the competence scale $(\mathrm{F}(1,187)$ $=4.975, \mathrm{p}<0.05)$. Regarding interaction between gender and sport status (Figure 1), female athletes had a higher appearance score than former female athletes and this

5 The model here corresponds to an incomplete factorial design and required a solution by an ad hoc calculation. difference was more noticeable than for men $(\mathrm{F}(1,186)=$ 35.306; $\mathrm{P}<0.01)$. The difference in support between male athletes and former male athletes was more significant than for women $(F(1,186)=4.61, p<0.05)$. Interactions between athletic status and sport modality were present for the four scale scores. Figure 2 shows that the differences between active athletes and former athletes for appearance $(\mathrm{F}(1,185)$ $=4.21, \mathrm{p}<0.05)$, importance $(\mathrm{F}(1,185)=18.063, \mathrm{p}<0.01)$ and support $(\mathrm{F}(1,185)=3.934, \mathrm{p}<0.05)$ favored the participants who competed or had compete in collective sports.

Effect sizes of sport status 6 on scale scores were calculated in order to quantify their relative importance. They were obtained using formula $d=t \times \sqrt{2 / n_{h}}$, where $n_{h}$ represents the harmonic mean of each sample size and $t$, the corresponding Student test. For scales of appearance, importance, competence and support, the effect sizes were $1.023 ; 1.118 ; 1.107$ and 0.741 . According to Cohen's (1988) criterion, these values may be considered quite high effect sizes. The support scale however clearly achieves a lower effect size amongst the scales. Results of the original study by Anderson (2004) were also calculated to compare them with the effect sizes of the present study ${ }^{7}$. The values were $0.675,0.945,0.744$ and 0.504 respectively for the same scales; here too, the support scale presents the lowest value. It can thus be seen that the effect sizes of the present study are globally higher than those of Anderson (2004), indicating that the disparity between athletes and non-athletes is clearer in the Québec sample.

\footnotetext{
${ }^{6}$ Calculations were made using athletes and non-athletes data as the Anderson sample does not include a subset of former athletes.

7 Idem 6
} 

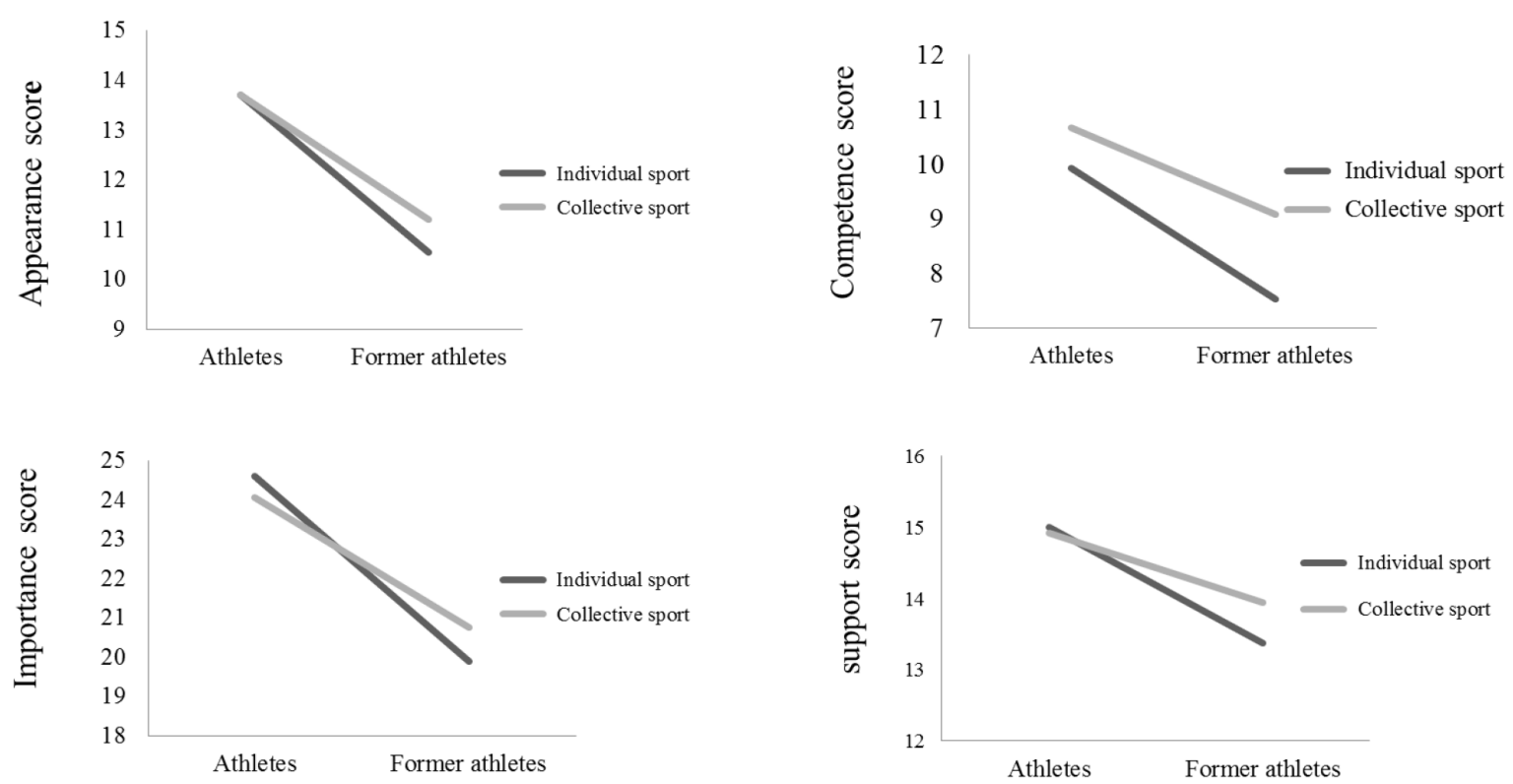

Figure 2. Interaction between sport status and sport modality for the four identity scales

Table 4. Correlations between AIMS and AIQ-French scales

\begin{tabular}{|c|c|c|c|c|c|}
\hline AIMS/AIQ & Appearance & Competence & Importance & Support & Total AIQ \\
\hline Social identity & $0.517^{* *}$ & $0.671^{* *}$ & $0.733^{* *}$ & $0.481^{* *}$ & $0.750^{* *}$ \\
\hline Exclusivity & $0.453^{* *}$ & $0.608^{* *}$ & $0.640^{* *}$ & $0.375^{* *}$ & $0.663^{* *}$ \\
\hline Negative affectivity & $0.236^{* *}$ & $0.230^{* *}$ & $0.366^{* *}$ & $0.231^{*}$ & $0.331^{* *}$ \\
\hline Total AIMS & $0.504^{* *}$ & $0.638^{* *}$ & $0.723^{* *}$ & $0.455^{* *}$ & $0.730^{* *}$ \\
\hline
\end{tabular}

* significant at $\mathrm{p}<0.05 * *$ significant at $\mathrm{p}<0.01$

Chronological age, which varies relatively little across participants, shows no correlation with scores obtained at different scales. The age of retirement was significantly correlated $(\mathrm{p}<0.05)$ with the appearance $(0.306)$, the importance (0.283) and the competence (0.207) scales. For athletes and former athletes, positive correlations between career lenght and each of the scales were observed and all were significant at $\mathrm{p}<0.01$. Weekly training hours did correlate significantly $(\mathrm{p}<0.05)$ with the competence $(0.147)$ and support (0.159) scales. Factor scores relationships with the descriptive variables were sensibly the same as the correlations with their reference scales were close to 1 .

Does the AIMS test, consisting of seven items grouped in three scales, correlate with our French version of the AIQ? Preliminary tests on the AIMS show strong item-to- item and item-to-scale correlations for items 1, 2, 3, 4, 5 and 7; however, the maximum correlation of item 6 with other items and scales is 0.101 . This item, "I lose confidence in myself when I am not good at sports /Je perds confiance en moi quand je ne suis pas bon(ne) en sport.", originates from the negative affective scale of Brewer and Cornelius (2001). The three inter-scale correlations of AIMS were 0.388 between negative affectivity and exclusivity, 0.417 between negative affectivity and social identity and 0.777 between exclusivity and social identity. The correlations of the AIQ scales with the AIMS total render rather high values, ranging from 0.455 to 0.723 . The correlations between the AIQ-French total and the AIMS scales vary between 0.331 and 0.750 , all small but significant at $\mathrm{p}<$ 0.01 (Table 4). The correlation between the AIMS and AIQ- 
French totals is $0.730(\mathrm{p}<0.01)$. The highest correlations are between social identity and the importance scales (0.733) and competence (0.671). Withdrawal of item 6 increased the overall AIMS' $\alpha$ value from 0.820 to 0.879 . Correlation between the AIMS first principal axis (6 items) and AIQ first principal component (17 items) was 0.772 . The correlation disattenuated by the alpha coefficients of each part, 0.879 and 0.935 respectively, becomes 0.851 .

\section{Discussion}

The purpose of this study was to validate a Frenchlanguage translation of the Athletic Identity Questionnaire (AIQ) by assessing its psychometric properties, based on a diversified sample of Québec respondents. Athletic identity is understood as a multi-faceted concept expressed in four subscales. The AIQ purpose is to verify the degree to which the individual is related to the athletic role by his/her own perceptions of athletic skills, physical appearance, the importance of sport and physical activity and the support he receives from others in the practice of sport. Our results, to the effect of high inter-scale correlations, show that there is a definite interdependence between the four dimensions of identity. The four high-level intra-scale correlations support the hypothesis of good cohesion within each scale. The Jackknife correction indicates that the positive correlation bias that each item induces on its own scale is less than $0.11(\mathrm{M}=0.105, \mathrm{SD}=0.035)$, varying from 0.045 to 0.156 from one scale to another. It is thus a further argument confirming the scales' internal consistency. Even after duly correcting the correlation that each item maintains with the total of its own scale, every item retains its main affiliation with its proprietary scale. Finally, Cronbach's $\alpha$ values support the argument of a good composition of all four scales. Thus, AIQ-French scales internal consistency and positive intercorrelations are amply confirmed. Classical EFA and ESEM with oblique inter-factor rotations have produced a four-factor structure, which corroborates the multidimensional aspect of AI alleged by Anderson (2004). The structure matrices obtained showed clusters of items that were a facsimile of the original scales of measurement, and the positive correlations between the obtained four factors confirm that they are indeed interrelated. However, it must be noted that the three correlations concerning the support factor appeared lower than the others. In other words, the matrix of inter-factor correlations shows that the support dimension is at a distance relatively to the other three. The strong link between the theoretical and statistical models is shown by the positive correlation coefficients, nearing 1 , between the factors and the corresponding scale scores. CFA corroborates the results of the EFA with acceptable indices of fit for this type of model. This study shows that the concepts of appearance, competence, importance and support, derived from the literature and embodied in the original AIQ (Anderson, 2004), are well represented statistically using the AIQ-French.

The analyses also revealed a second-order factor model, summing up to a two-level hierarchical structure. The upper level consists of two components, slightly correlated with each other $(\rho=0.316)$. Contrary to the results of Anderson (2004), it seems that the overall concept of AI does not include the four first order factors obtained previously. Indeed, the first higher order component incorporates elements that presumably make up the theoretical sporting identity of Anderson (2004), namely physical appearance, self-perceived athletic competence and the importance attached to sport and physical activity. The second lesser component is the support from others to practice sports. It explains a smaller part of variance, while being slightly linked to the first component. This dimension may not be specific to athletic identity, but refer more generally to any professional or socially recognized role. The resulting model of AI thus seems to be a clearly defined and unique construct, composed of the afore-mentioned three facets, and not including the support dimension. The second-order structure we obtained differs from that reported by Anderson (2004), who advocated integration of the four starting dimensions. It appears that the degree to which individuals identify with the role of athlete is measurable by the three concepts mentioned above. The social aspect is indeed related to AI, but not as an intrinsic or essential part. The dimension of support thus seems to be a complement and 
not a specific ingredient of the athlete's self-definition. The "support to do an activity linked to a status" tends rather towards a social support parameter and would relate here to the athlete in his public role and social interactions (Nasco \& Webb, 2006), which is not intrinsically related to his practice. This social side of the athlete's life can be influenced by family, friends, coaches and their attitude towards the athlete and his sport practice. The explanation would be that these environmental choices are linked to this social side of the athlete's occupation, the athletic role being influenced by environment (Brewer et al., 1993). The support of others can become a source of external constraint to practicing a sport. This may mean the individual feels obligated to "fit" with his role as an athlete even when he or she is engaged in other activities. Support can serve as a motivation to practice, but it is not necessarily included within the identity construct. A person can receive support from those around him for physical activity as a hobby or simply as a way to improve personal health.

The stratification of the sample according to the level of engagement in sport made it possible to better show the AIQ-French ability to distinguish among different groups. Inter-group comparisons show the decline in identity scores with decreased sport involvement (athletes > former athletes $>$ non-athletes) ${ }^{8}$. This is true for the four scales regardless of participants' gender. These results are consistent with those of Nasco and Webb (2006) who found significant differences between athletes and non-athletes. Comparing AA, FA and NA individuals made it possible to establish the sensitivity of the test in relation to sporting status. A sports person, an athlete, should have a higher sporting identity than one who does not practice or never practiced sport (Lamont-Mills \& Christensen, 2006). One reason behind this might be the accumulation of past experiences in sport (Horton \& Mack, 2000). Another explanation is that post-career athletes undergo a change in identity that corresponds to the formation of a new social

8 These observations are also expected for the analyses of variance with the factor scores, because the four factors obtained by EFA were almost a copy of the four starting scales. status (Taylor \& Ogilvie, 1994). The discriminating ability of the AIQ-French towards people with different levels of sport participation is an additional argument in favor of the construct validity of the present test.

Men, regardless of their sport status, display a more important AI (appearance, competence, importance) than women. This suggests that men in general seem to identify more with the role of athletes than women (Wiechman \& Williams, 1997). It seems that men's athletic identity will be more important, even if they do not practice or have never practiced sports as athletes. This relates to what Good, Brewer, Petitpas, Van Raalte, and Mahar (1993) have demonstrated, namely that the difference in athletic identity among non-athletes significantly favors men. The physical appearance appears however to be more important for women athletes than for male athletes. This observation is in line with the reality observed in the meta-analysis of Hausenblas and Downs (2001) that revealed no difference between female and male athletes in body image perception. A significant score decrease in physical appearance between women athlete and former athlete suggests that body image is less important for women in post-career women than for men. These results suggest that the self-image, without being associated more to women, is particularly valued while they practice sport.

Present or past participation in team sports generally seems to lead to a higher overall level of AI than the practice of individual sport. These findings support the theory that the nature of sport affects athletic identity (Chen, Snyder, \& Magner, 2010). However they differ from Hadiyan and Sheikh (2015), for whom AI is less important for team sport athletes since it is divided between each member of the team, while in individual sport each is deeply invested in its own performance. It is also possible, and even probable, that the cultural differences between the present and previously studied populations are at the origin of this disparity.

The differences between AA and FA in the four AI scales were greater for individual sports than for team sports. It appears, therefore, that the individual sport athlete sees a more serious decrease in his or her identification with the 
athletic role than if he had previously practiced a team sport. It is possible that for the same level of AI, athletes in individual sports may be more affected at the end of their careers due to a deep and solitary investment in sports performance. The loss of social benchmarks (i.e. coach, training partners) at career's end may account for this significant decline in the level of identification with the athletic role.

Results showed an important effect of athletic status on scale measures for each of the four facets of sports identity proposed. Cohen (1988) values of effect size greater than 1, for the scales of appearance, competence and importance, indicate a very strong relationship with athletic status. As for the support scale, it differs from the other three with a magnitude of almost high effect but well under 1 . This scale of social support appears to be more loosely linked to the level of athletic status than the principal component of athletic identity. Comparing these results with those of Anderson (2004), it can be seen that, though globally smaller, similar differences in effect size indices are present. The support is again the variable showing the least effect in relationship to the athletic status. The comparison between the two studies shows that, in a French Québec context, physical appearance, sport competence and importance of sport are influenced very strongly by athletic status. One explanation could be that Québec athletes have a more notable and socially distinctive status than American athletes, perhaps because they are fewer in number in Québec compared to the United States. Notwithstanding these cultural differences, social support has a lesser impact among the four AI scales. As a result, the AIQ test measures three conceptual dimensions that, while related to athletic status, are greatly influenced by a person's level of commitment in sport or physical activity. The social dimension of support appears as an external addition.

The literature presents several instruments attempting to identify AI, one of the most cited and used being the AIMS of Brewer et al. (1993). The French version of this questionnaire was used as a concomitant benchmark to validate our French version of the AIQ. First, it seems that the relationship between AIQ and AIMS, as measured by the correlations between the various scales, is positive and significant.
Therefore, the two tests seem to measure concepts that generally vary in a common way, after the pruning of a discordant AIMS item. More precisely, AI measured by the combination 'appearance-competence-importance' correlates with AI measured by the six selected AIMS items. The correlation, after deattenuation, indicates that these two measurements are very close to each other, sharing $85 \%$ of their true variances, but also that they are not identical, each having a complementary specificity of about $15 \%$. This makes it possible to say that the French-Canadian versions of the AIQ and AIMS are two instruments that measure, to a very large extent, a central concept to which the literature refers as the athletic identity. This confirms that the AIQ-French is a fully-fledged tool capable of measuring the individual's self-identification in the athletic role from different dimensions of what already existed in the literature.

The validity of the AIQ-French is also expressed by the importance of the relationships between the different scales and the descriptive variables of age, retirement age, training hours and career length. Age did not seem to have any relation to AI scores for both athletes and ex-athletes as for non-athletes. This is in contrast to the work of Miller and Kerr (2003) for whom a negative relation exists between this variable. One possible interpretation would be that athletic identity must first and foremost be linked to the individual's interest in the practice of physical activity and sport regardless the passing of time.

The duration of the sport career covaries positively with each of the scale scores obtained. It seems that the longer an individual is imbued with the sporting context, the greater his or her overall sporting identity will be. More precisely, a long career affects both impressions of one's own physical appearance and perceived competence as an athlete. Practicing a sport over a long period may ensure that it is prioritized at the expense of other activities. The AIQ-French reflects the evolution of the athletic identity related to the individual's sport immersion duration. Finally, the perception of family and friends support will be more anchored if an athlete practices a sport on a regular and long-term basis. 
Hours spent in training appear to be related to the competence in sport score. Just like the length of the career, spending a lot of time training helps to identify with the role of athlete. The correlation between the number of hours of practice and competence shows the specificity of the measure proposed by the AIQ. Defining oneself as competent in sport and physical activity therefore requires regular actions in the sport training context. The individual can even perceive him or herself or be perceived by his entourage as an athlete better able to practice his sport. Time spent training can draw the admiration and compliments of those around, which may lead the athlete to rely on others' perceptions regarding sport.

The age of retirement is positively associated to the three facets of AI (appearance, competence, importance). The older the athlete is at retirement, the more likely the athletic career did occupy a large part of his or her life or the more mature portion of the athlete's existence. Physical appearance seems to become increasingly important over time for former athletes. The physical aspect, which is always put in the forefront during the sport career, does not receive the same consideration once it is over. The age of retirement appears to be positively related to the sport competence dimension. This end-of-career may be strongly related to a lost of skills or diminished performance (Sinclair \& Orlick, 1993). The same could be true for the importance of sport and physical activity since exercise is a means used by athletes to facilitate his transition to a new career (Sinclair and Orlick, 1993).

From the beginning, we planned to include athletes, former athletes and non-athletes in the sample. The purpose of this segmentation was to ascertain whether the instrument would make it possible to distinguish between groups according to their different levels of involvement in sport. Measuring "athletic identity" in a population with little or no connection to sport would probably not have produced such clear results. The inclusion of three distinct athletic statuses in the sample is therefore an asset of the present study. Such a division of the sample could have benefited Anderson (2004) because it helped confirm explicitly, even definitely, the conceptual validity of the instrument. Another adavantage of this study is the method of factor analysis used. The use of classical factor analysis with oblique rotations, allowed showing the natural organization of the data and the ESEM supports these structures. This development suggests that, without imposing a predetermined structure on the information obtained, a descriptive model of reality can be identified without compromising its validation. The supplementary confirmatory analysis (CFA) finally sanctioned the results of the previous analyzes.

The first limits of this study concern sampling. Most of the participants were university students, so it is not prudent to generalize the results to the entire Québec population, even if a large proportion of athletes naturally attend university at a point in their life. Although two-thirds of the participants were women, AI first and second order factorial structures were the same. Finally, as with any self-reported measure, social desirability may have affected scores on certain scales, such as appearance or skill.

\section{Conclusion}

The present results show that AIQ-French is a valid test for measuring athletic identity, a test whose multifactorial structure is consistent both internally and externally. The overall psychometric concept of sport identity is precisely represented by three scales: importance, appearance and competence, the scale of support being a complement to this construct. The ability of the AIQ-French to distinguish individuals according to their sporting status is a decisive argument for its discriminating validity. The nearly perfect relationship observed between the scales and the corresponding factor structure reinforces Anderson's theory and warrants the practical use of the tool. The measurement of the level of sport self-identification on a large population of athletes and former athletes (sports retirement, drop-out) could therefore be envisaged for a predictive purpose, stratifying according to the sporting context. It has been shown that scales of appearance, competence and importance have a connection with physical activity practice (Anderson, 2004) and lifestyle habits. This connection could help predict practice based on an individual's sport status and 
thus better understand the impact of post-career transition on lifestyle and health.

\section{Conflict of Interest}

The authors declare no conflict of interest and that the present manuscript has not been published elsewhere and that it has not been submitted simultaneously for publication elsewhere.

\section{References}

Anderson, C. B. (1995). The Athletic Identity Questionnaire: Development, initial validation, and relation to the stages of exercise adoption. (56), ProQuest Information \& Learning, US. PsycINFODatabase Record database. Anderson, C. B. (2004). Athletic identity and its relation to exercise behavior: scale development and initial validation. Journal of Sport \& Exercise Psychology, 26(1), 39-56.

Anderson, D. F., \& Cychosz, C. M. (1994). Development of an exercise identity scale. Perceptual and Motor Skills, 78(3), 747-751.

Asparouhov, T., \& Muthén, B. (2009). Exploratory structural equation modeling. Structural Equation Modeling: A Multidisciplinary Journal, 16(3), 397-438.

Brewer, B. W., \& Cornelius, A. (2001). Norms and factorial invariance of the Athletic Identity Measurement Scale. Academic Athletic Journal, 15(2), 103-113.

Brewer, B. W., Van Raalte, J. L., \& Linder, D. E. (1993). Athletic identity: Hercules' muscles or Achilles heel? International Journal of Sport Psychology, 24(2), 237-254.

Chen, S., Snyder, S., \& Magner, M. (2010). The effects of sport participation on student-athletes' and non-athlete students' social life and identity. Journal of Issues in Intercollegiate Athletics, 3(1), 176-193.

Cieslak, T. J. (2004). Describing and measuring the athletic identity construct: Scale development and validation. The Ohio State University, Retrieved fromhttps://searchproquest-com.biblioproxy.uqtr.ca/docview/30514028 0?accountid=14725 ProQuest Dissertations \& Theses
Global database.

Curry, T. J., \& Weaner, J. S. (1987). Sport identity salience, commitment, and the involvement of self in role: measurement issues. Sociology of Sport Journal, 4(3), 280-288.

Good, A. J., Brewer, B. W., Petitpas, A. J., Van Raalte, J. L., \& Mahar, M. T. (1993). Identity foreclosure, athletic identity, and college sport participation. The Academic Athletic Journal, 8, 1-12.

Gorsuch, R. L. (1983). Factor Analysis: L. Erlbaum Associates. Gorsuch, R. L. (1988). Exploratory factor analysis. In Handbook of multivariate experimental psychology (pp. 231-258): Springer.

Hadiyan, H. M., \& Sheikh, M. (2015). How different Sports establish different athletic identity levels. International Journal of Kinesiology \& Sports Science, 3(3), 28.

Hausenblas, H. A., \& Downs, D. S. (2001). Comparison of body image between athletes and nonathletes: a metaanalytic review. Journal of Applied Sport Psychology, 13(3), 323-339. doi: 10.1080/104132001753144437

Hin Yue, L., \& Andersen, M. B. (2008). Athletic identity in China: Examining the AIMS in a Hong Kong sample. International Journal of Sport \& Exercise Psychology, 6(2), 176-188.

Holland, D. (1997). Selves as cultured. In R. D. Ashmore \& L. Jussin (Eds.), Self and Identity. Fundamental issues (pp. 160-190). Oxford: Oxford Univ. Press.

Horton, R. S., \& Mack, D. E. (2000). Athletic identity in marathon runners: Functional focus or dysfunctional commitment? Journal of Sport Behavior, 23(2).

Hu, L. t., \& Bentler, P. M. (1999). Cutoff criteria for fit indexes in covariance structure analysis: Conventional criteria versus new alternatives. Structural Equation Modeling: A Multidisciplinary Journal, 6(1), 1-55. doi:10.1080/10705519909540118

Joreskog, K. G. (1969). A General Approach to Confirmatory MaximumLikelihood Factor Analysis. Psychometrika, 34(2p1), 183-202. doi: 10.1007/Bf02289343

Kendzierski, D. (1988). Self-Schemata and Exercise. Basic and Applied Social Psychology, 9(1), 45-59. doi: 10.1 207/s15324834basp0901_4 
Kendzierski, D. (1990). Exercise self-schemata: Cognitive and behavioral correlates. Health Psychology, 9(1), 69-82. doi:10.1037/0278-6133.9.1.69

Lamont-Mills, A., \& Christensen, S. A. (2006). Athletic identity and its relationship to sport participation levels. Journal of Science and Medicine in Sport, 9(6), 472-478. doi: 10.1016/j.jsams.2006.04.004

Laurencelle, L. (1998). Théorie et techniques de la mesure instrumentale: Presses de l'Université du Québec.

Markus, H., Cross, S., \& Wurf, E. (1990). The role of the self-system in competence. In R. J. Sternberg \& J. Kolligian (Eds.), Competence Considered. New Heaven, NJ: Yale University Press.

Martin, J. J., Eklund, R. C., \& Mushett, C. A. (1997). Factor structure of the athletic identity measurement scale with athletes with disabilities. Adapted Physical Activity Quarterly, 14(1), 74-82.

McCall, G. J., \& Simmons, J. L. (1966). Identities and interactions. New York, NY, US: Free Press.

Miller, P. S., \& Kerr, G. A. (2003). The role experimentation of intercollegiate student athletes. Sport Psychologist, 17(2).

Nasco, S. A., \& Webb, W. M. (2006). Toward an Expanded Measure of Athletic Identity: The Inclusion of Public and Private Dimensions. Journal of Sport \& Exercise Psychology, 28(4), 434-453.

Proios, M. (2012). Factor validity of the Athletic Identity Measurement Scale in a Greek sample. International Journal of Sport \& Exercise Psychology, 10(4), 305-313.

Schmid, J., \& Seiler, R. (2003). Identität im hochleistungssport: Überprüfung einer deutschsprachigen Adaptation der Athletic Identity Measurement Scale (AIMS-D). Diagnostica, 49(4), 176-183. doi: 10.1026//0012-1924. 49.4.176

Silva, W. R. d., Ferrari, E. P., Medeiros, T. E., Freitas, K. T. D. d., Tkac, C. M., \& Cardoso, F. L. (2016). "Athletic Identity Measurement Scale": Translation, Adaptation and Validation for Brazil. Motriz: Revista de Educação Física, 22, 42-47.

Sinclair, D. A., \& Orlick, T. (1993). Positive transitions from high-performance sport. Sport Psychologist, 7(2),
$138-150$

Sohrabi, M. (2012). Determining validity and reliability of Athletic Identity Measurement Scale (AIMS-Plus) among Iranian sample. Archives des Sciences, 65.

Stambulova, N., Stephan, Y., \& Japhag, U. (2007). Athletic retirement: Across-national comparison of elite French and Swedish athletes. Psychology of Sport and Exercise, 8(1), 101-118. doi: 10.1016/j.psychsport.20 06.05 .002

Stryker, S., \& Serpe, R. T. (1982). Commitment, identity salience, and role behavior: Theory and research example. In W. Ickes \& E. S. Knowles (Eds.), Personality, Roles, and Social Behavior (pp. 199-218). New York, NY: Springer New York.

Swann, W. B. (1983). Self-verification: Bringing social reality into harmony with the self. Social psychological perspectives on the self, 2, 33-66.

Tabachnick, B. G., \& Fidell, L. S. (2007). Using multivariate statistics (5th ed.). Boston, MA: Allyn \& Bacon/Pearson Education.

Taylor, J., \& Ogilvie, B. C. (1994). A conceptual model of adaptation to retirement among athletes. Journal of Applied Sport Psychology, 6(1), 1-20. doi: 10.1080/10 413209408406462

Thorburn, D. (1976). Some asymptotic properties of Jackknife statistics. Biometrika, 63(2), 305-313. doi:10. $2307 / 2335624$

Vallerand, R. J. (1989). Vers une méthodologie de validation trans-culturelle de questionnaires psychologiques: Implications pour la recherche en langue française. Canadian Psychology, 30(4), 662.

Visek, A. J., Watson, J. C., Hurst, J. R., Maxwell, J. P., \& Harris, B. S. (2010). Athletic identity and aggressiveness: A cross-cultural analysis of the athletic identity maintenance model. International Journal of Sport and Exercise Psychology, 8(2), 99-116. doi: 10.1080/ 1612197X.2010.9671936

Wiechman, S. A., \& Williams, J. (1997). Relation of athletic identity to injury and mood disturbance. Journal of Sport Behavior, 20(2), 199-210. 